\title{
Energy Strategy of Japan after Fukushima Atomic Power Station Accident
}

\author{
Yuzuru Ashida ${ }^{1}$ \\ ${ }^{1}$ Professor emeritus of Kyoto University, \\ President NGO Environment Energy Forestry and Agriculture Network (ashida@eefa.jp)
}

\begin{abstract}
Human beings are now enjoying the highly advanced civilization supported by cheap and abundant oil and natural gas. However, the International Energy Agent (IEA) has declared in November, 2010 that the oil production had already peaked in 2006. In Japan, on 11, March, 2011, the miserable disaster earthquake and tsunami caused not only the damage of human life and property, but also the accident in Fukushima No. 1 atomic power station emitted the abundant high-level radio active waster. The energy strategy of Japan before accident that will depend on the increase of ratio of nuclear power generation from $29 \%$ to $50 \%$ in 2030 was reviewed. Consequently, the renewable energy was noticed as next generation energy instead of nuclear power. Fortunately, in Japan, we have many environment and renewable energy already in the stage of commercial level, Here, I introduce the energy strategy of Japan after Fukushima atomic power station accident and the renewable energy in Japan.
\end{abstract}

\section{WORLD ENERGY CIRCUMSTANCES}

IEA reported that oil production in the world passed the peak. The background of oil peak is as follows.

- Oil depletion in North Sea faster than anticipated.

- Reservoir pressure in Saudi Arabian oil fields maintained by water injection raising water cut also observed.

- Discovery of new oil reserve peaked ca. 40 years ago.

- Oil production may have peaked in 2006.

- Oil demand is still growing up rapidly especially due to industrialization of BRIC's countries.

- Oil reserve based on the finite amount never exhausted but being depleted so as to instability brought to oil price.

Though the problem is easy to fix if we can get the alternative energy reserve instead of oil, unfortunately it might be very difficult.

\section{NEW ENERGY STRATEGY}

Japanese government issued the eco/energy fundamental strategy in 2012. The essence of it is listed in Table 1.
Table 1 Eco/energy fundamental strategy

Energy policy before accident : Nuclear power generation from $29 \%$ to almost $50 \%$ by 2030 .

Energy policy in 2030 after accident

1. realization of the society without nuclear power

(1) three principles

- severe remit of operation beyond 40 years

- if safety is not confirmed, re-operation of atomic power station is not approved

- no new construction and no increase of existing station

(2) five policies

- promotion of nuclear waste cycle

- maintenance and strength of man of talent and technology

- cooperation with international society

- strength of counter-plan for area approved the introduction of atomic power station

- establishment of operation system and compensation system for damage

2. green energy revolution

(1) economy in power consumption : more than $110 \mathrm{TWh}$ by 2030

(2) conomy in energy : more than 72 million $\mathrm{kl}$ by 2030

(3) renewable energy supply : more than $300 \mathrm{TWh}$ (three times than present)

3. stable energy supply

(1) high level utilization of thermal power 
generation

(2) high level utilization of thermal energy by cogeneration system etc.

- $150 \mathrm{TWh}$ (five times than present) by 2030

(3) development of technology related to next generation energy

(4) stable and cheap securement and supply of fossil energy

The law of Feed-in Tariff (FIT) was published on 1st, July, 2012. The cost and period of each renewable energy are shown in Table 2. The surcharge related to renewable energy installed is charged to users.

Table 2 Cost and period of FIT

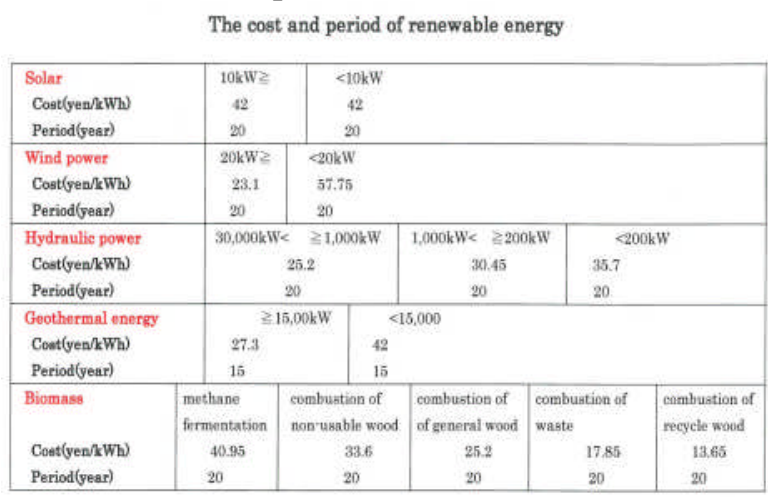

\section{RENEWABLE ENERGY TECHNOLOGIES}

Fortunately, we have many environmental and energy technologies of the next generation that are practical and environmentally friendly in the university and the company in Japan. I would like to introduce such technologies in this paper.

\section{(1) Image map of eco-park}

I have proposed the concept of a eco-park that are schematically mapped in Fig.1. The park stands for self-support of energy that could be built using technologies on the practical stage that are available in Japan.

\section{(2) Sub-critical water technology}

The boiling point of water is $100^{\circ} \mathrm{C}$ at $0.1 \mathrm{MPa}$. If the pressure is added to reach $22 \mathrm{MPa}$, it becomes super-critical water at $374^{\circ} \mathrm{K}$. At either the lower pressure or the lower temperature than the critical point, the water becomes sub-critical. Sub-critical water could be used to process squidgy waste (Yoshida and Tavakoli, 2004). Sub-critical water has the hydrolysis power to dissolve the organic materials like sewage mud, or powdered borne even polluted by BSE into the valuable material like amino acid, phosphoric acid, methane gas and

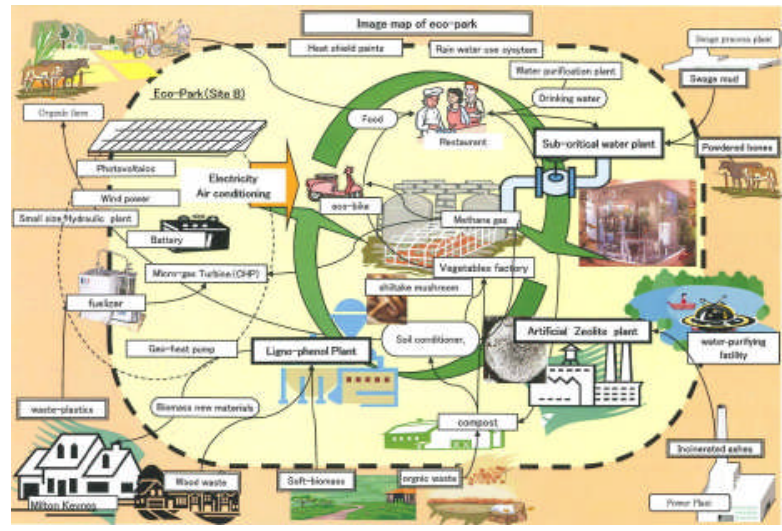

Figure 1 Schematic map of eco-park concept.

fertilizer. The extracted methane gas is used to generate the electricity and after purification, sent to gas station for fuel to motor bike and car. The car and motor bike with originally gasoline engine by changing only gasoline tank to methane gas tank.

\section{(3) Wind power turbine}

A wind turbine composed of a rotor and a circular sword was developed and named as wind lens wind mill (Toshimatsu, et al., 2008). The eddy current occurs when attaching the sword around a rotor. The wind is then concentrated in the central portion of wind turbine due to the decreased pressure by eddy current so as to generate the electric power of 2 to 5 times more than the conventional one. This wind turbine has the following characteristics: (i) Higher output : $2 \sim 5$ times than the conventional one, (ii) Safety : the prevention of touch, scatter of rotor by diffusion, (iii) Lower noise : sharp decrease in the noise from the rotor by diffusion, and (iv) Rotor direction control : automatic direction control of rotor normal to the direction to wind by the attached sword. The installation of an offshore wind power mill of $50 \mathrm{MW}$ has been planned in near future.

\section{(4) Artificial zeolite}

Zeolite is material composed of silicon and aluminum. Professor Henmi (Ehime University) developed the technology to generate the artificial zeolite from coal ash (Ando, et al., 2003). The artificial zeolite has the characteristics of the absorption of harmful objects such as heavy metal, deodorization, etc., and could be exploited for the soil improvement, for the promotion of the growth of plant, or for composts.

\section{(5) Ligno-phenol technology}

Wood material is composed of the cellulose of the cage structure and the piled lignin. Because of the structural complexity, these two materials are 
processed without decomposing them when recycling woody materials and caused some limitations in the number of recycling times. A technique to separate the lignin and carbon-hydrate by only stirring at normal temperature and pressure after adding phenol was developed (Funaoka, et al., 1995). Carbon-hydrate becomes the glucose by hydrolysis and the pilled lignin is dissolved into each piece by processing using sulfuric acid. The dissolved lignin called "Ligno-phenol" is used the raw materials for chemical industries to make plastic, film, adhesive etc.

\section{(6) Geothermal energy}

Geo-thermal power generation is considered as no- $\mathrm{CO} 2$ emission, clean and renewable energy. As there are many volcanically or geothermal-active places in Japan, we could exploit the abundant geothermal potential. The total power of geothermal reservoirs in Japan is estimated almost $23,400 \mathrm{Mw}$ corresponding to 23 units of nuclear power plant of $1,000 \mathrm{Mw}$ when comparing in the electricity generation. Among those geothermal-potential reservoirs, already-developed, confirmed, and theoretically-estimated geothermal potentials are $1 \%, 9 \%$ and the rest, respectively. The reason why the development has not been advanced is, the severe regulations to protect national and natural parks from any development, strong opposition by hot spring societies, and the technical and cost issues involved in geothermal development itself. If these problems are cleared, the power generation jumps from the current $535 \mathrm{Mw}$ (the 8th place in the world) up to $23 \mathrm{kMw}$. Conventional geo-thermal electric power generation uses the vapor whose temperature exceeds over $150^{\circ} \mathrm{C}$. For hot water whose temperature is lower, materials whose boiling point is much lower like pentane (boiling point of $36^{\circ} \mathrm{C}$ ) could be used to rotate the turbine. For the utilization of two different liquids of different boiling points to be used, the system is called binary cycle. Not only geothermal, but also the thermal energy emitted from industrial plants like iron works could also be used as energy source as far as they waste heat energy. For example, the Kalina cycle, one of the binary cycle, was developed (Kalina and Leibowitz, 1987). A steam turbine is rotated to generate the electricity by vapor ammonia through a thermal exchanger. Boiling point of pure ammonia is $-33.48^{\circ} \mathrm{C}$. The mixture with water changes the boiling point depending on the volumetric fraction. Therefore, the technique is applicable to various temperature ranges. The development of the Kalina cycle of $50 \mathrm{kw}$ power generation is to be achieved by the end of 2011 in Japan.

\section{(7) Geo-heat pump}

The temperature at depths of $100 \sim 500 \mathrm{~m}$ in the underground would be kept is about $15^{\circ} \mathrm{C}$ throughout year at middle latitude area in the earth due to ground water circulation. On the other hand, if the air temperature in summer and in winter is assumed to be $30^{\circ} \mathrm{C}$ and $0^{\circ} \mathrm{C}$, respectively, the temperature difference of $15^{\circ} \mathrm{C}$, i.e., the thermal energy gap, always exists between the air and the underground. The circulation of water in the drilled well of $100 \sim 500 \mathrm{~m}$ depth, the difference in the temperature of $15{ }^{\circ} \mathrm{C}$ could be used for air-conditioning both in summer and in winter. Moreover the air conditioning, Geo-Heat Pump (Geo-HP) could be used for melting snow on road without spreading water.

\section{(8) Geo-sequestration}

When gas of carbon-dioxide (CO2) from steam power plant is injected into coal seam, methane gas (CH4) could be recovered in the replacement with $\mathrm{CO} 2$ in the plenty amount of pores in the coal seam. Recovered $\mathrm{CH} 4$ could be used as auxiliary fuel of steam power plant. Laboratory experiments showed that the absorption of coal to $\mathrm{CO} 2$ is about two to several times than that to $\mathrm{CH} 4$. A field experiment (Yamaguchi, et al., 2007) in Yubari coal mine in Hokkaido Island from 2002 to 2009 for six years. Two wells were drilled, one vertical well is for the injection of $\mathrm{CO} 2$, and the other deviated well for the recovery of $\mathrm{CH} 4$. The bottom of two wells is placed apart for almost $50 \mathrm{~m}$. Their experimental results indicated that the amount of methane gas recovered during the experiment was several times compared without injection of $\mathrm{CO} 2$ that was injected almost 3 to 10 tons/day at maximum.

\section{(9) Biomass to liquid (BTL)}

Biomass is also an example of the renewable energy and is converted to mixed oil using Fischer-Tropsch (FT) synthesis reaction technology (Larson and Jin, 1999). The mixed oil is then used for the electricity generation, fuel, and, the thermal energy of steam. This system could be regarded as tri-generation system. A demonstration plant for the system is now to be inaugurated in Tokushima prefecture.

\section{(10) Bio diesel fuel (BDF)}

The waste tempura oil is gathered from residences, shops, restaurants and factories for the refinement in a plant of Kyoto City to BDF to fuel their public buses, or garbage trucks and, cargoes. Not only the waste tempura oil but also the 
extracted oil from Jatroha tree are used as crude source of BDF. The production of BDF at this plant produces is about $30 \mathrm{kl} /$ day. Recently, the BDF produced at the plant has been exported to Holland for fueling diesel cars and aircrafts.

\section{(11) High quality potable water purification equipment}

The supply of potable water is one of the most serious problems for the survival of human beings, especially for the underdevelopment countries in the world. Recently, water could be polluted by the poisonous toxic chemical like nitrate nitrogen, dioxin, trihalomethane, etc. A Japanese company developed water purification equipment using high quality reverse osmosis membrane of 0.001 micron diameter pore to filtrate out the completely pure water by the support of Japan Aerospace Exploration Agency (JAXA) for the supply of potable water to persons in space station. Because of a nano-scale filtration, this equipment can be used to filtrate rain and river water, bathwater, pool-water, pond water and water for extinguishing fire and even seawater. Three types of the equipment have been developed: home-use, trunk-type and portable type. The portable type would filtrate out purified water of $150 \sim 200 \mathrm{l} / \mathrm{hr}$ (water demand of $1200 \sim 1600$ persons) for sweet water and $50 \sim 80 \mathrm{l} / \mathrm{hr}$ (water demand of $400 \sim$ 600 persons) for brine.

\section{(12) Small scale hydroelectric power}

A fall of water of $1 \mathrm{~m} 3 / \mathrm{hr}$ generates the electricity of almost $7 \mathrm{kw}$. A turbine could be driven by the falling water in river or in sewage treatment plant. A full-scale hydroelectric power plant installed in real river would generate the electricity of $2,300 \mathrm{kw}$ and the addition of the siphon system would add 0.2 $\sim 5 \mathrm{kw} / \mathrm{h}$. A spiral-type turbine for the low volume of water with the low water-head difference would generate $30 \mathrm{w} / \mathrm{h}$ using only 11 litter/s of water.

\section{(13) Intercept/absorbing materials}

Coating paint or film on glass window by heat scattering or low albedo material with truly spherical ceramic balls of 0.2 micro meters would scatters and absorbs the ultra-violet rays and the near infrared radiation. These scattering phenomena could be utilized to coat a building with the paint or films to keep the inside temperature comfortable (Ohkawa et al., 2011).

\section{CONCLUSION}

Our human beings are nowadays enjoying the highly advanced civilization supported by the petroleum. However, the reserves of petroleum and even of uranium are finite. We should not pass the negative debt of the destruction of the earth environment to the next generation. In order to cope with the problems in energy and environment, everyone of us must focus on the utilization of renewable energy from the point of view as a cosmopolitan person. Since the renewable energy is borderless over countries or mining areas, we can use it if we have the technology. Though the earth is not puzzled without the human beings, the human beings should be on the earth and there is no other place to live outside of the earth.

ACKNOWLEDGMENT: The author thanks Professor Hitoshi Mikada of Kyoto University for preparing and brief-reviewing the manuscript.

\section{REFERENCES}

1) Ando, T., Saito, M., Muramatsu, S., Hiyoshi, K., Haruna, J., Matsue, N., and Henmi, T. (2003): The Synthesis of Zeolite from Paper Sludge (PS) Associated with Its Carbonization, Kami $\mathrm{Pa}$ Gikyoshi/Japan Tappi Journal, 57 (12), 1829-1837.

2) Ashida, Y. and Mikada, H. (2006): Recognition of oil peak in Japan, Proc.,8th SEGJ INT. SYMP., 13-15.

3) Funaoka, M., Matsubara, M., Seki, N., Fukatsu, S. (1995): Conversion of native lignin to a highly phenolic functional polymer and its separation from lignocellulosics, Biotechn. Bioeng., 46 (6), 545-552.

4) International Energy Association (2010): World Energy Outlook 2009.

5) Kalina, A.L., Leibowitz, H.M. (1987): Applying Kalina technology to a bottoming cycle for utility combined cycles, American Society of Mechanical Engineers (Paper), 6 p.

6) Larson, E.D., and Jin, H. (1999): Biomass Conversion to Fischer-Tropsch Liquids: Preliminary Energy Balances, Proc. 4th Biomass Conference of the Americas, I, 843-853.

7) Ohkawa, E., Mikada, H., Goto, T.-n., Onishi, K., Takekawa, J., Taniguchi, K., and Ashida, Y. (2011): Suppression of insolation heating using paint admixed with silica spheres - An approach from infrared band electromagnetic scattering, Phys. Chem. Earth, 36, 1412-1418.

8) Toshimitsu, K., Nishikawa, K., Haruki, W., Oono, S., Takao, M., and Ohya, Y.(2008): PIV measurements of flows around the wind turbines with a flanged-diffuser shroud, J. Thermal Sci., 17 (4), pp. 375-380.

9) Yamaguchi, S., Ohga, K., Fujioka, M., Nako, M. 
(2007): History matching on micro-pilot tests of $\mathrm{CO} 2$ sequestration and ECBM in the ishikari coal field, Nihon Enerugi Gakkaishi/Journal of the Japan Institute of Energy, 86 (2), 80-86.

10) Yoshida, H., and Tavakoli, O. (2004): Sub-critical water hydrolysis treatment for waste squid entrails and production of amino acids, organic acids, and fatty acids, J. Chem. Eng. Jpn., 37 (2), 253-260. 
